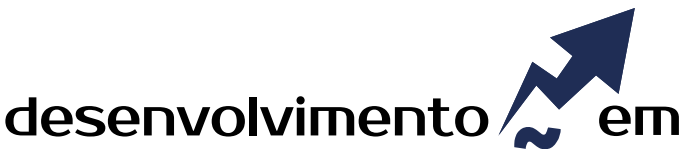 QUESTÃO
}

\section{Importância Socioeconômica da Integração Avícola para os Produtores da Mesorregião Oeste do Paraná}

\author{
http://dx.doi.org/10.21527/2237-6453.2019.49.329-347
}

Recebido em: 4/6/2018

Aceito em: $11 / 6 / 2019$

Ivanete Daga Cielo, Weimar Freire da Rocha Júnior², Fernanda Cristina Sanches-Canevesi ${ }^{3}$

\begin{abstract}
RESUMO
A avicultura é um setor em expansão e representativo para a economia brasileira. No Estado do Paraná (maior produtor e exportador de carne de frango do país) o sistema agroindustrial (SAG) assume maior destaque representando $11 \%$ do valor bruto da produção do agronegócio. Este SAG é também o maior gerador de emprego e renda do agronegócio paranaense, contribuindo para o aumento significativo da economia estadual. Ademais, dos setores do agronegócio a avicultura é o que tem maior potencial de geração de empregos, haja vista que demanda muita mão de obra para produção e industrialização. Nesse cenário, como objetivo central, este estudo buscou investigar os impactos socioeconômicos da atividade avícola para produtores de frango de corte da Mesorregião Oeste Paranaense (MROP), bem como identificar o perfil e características desses sujeitos. Para tanto, este estudo, de cunho qualitativo, reflete os resultados de um questionário aplicado in loco a 133 avicultores da MROP. Os principais resultados mostram que a atividade é regida contratualmente entre produtores e agroindústrias pelo denominado sistema de integração avícola, e composta pelo predomínio de produtores com pequenas propriedades. Estes demonstram-se, de modo geral, satisfeitos, tanto em relação à lucratividade quanto à garantia do retorno sobre o investimento realizado em suas propriedades. De modo geral, os resultados apontam para um cenário favorável à avicultura na região estudada, avaliada de forma positiva pelos agentes envolvidos.
\end{abstract}

Palavras-chave: Agronegócio. Avicultura. Sistema agroindustrial.

\section{SOCIOECONOMIC IMPORTANCE OF AVICULTURAL INTEGRATION FOR THE PRODUCERS OF THE WEST REGION STATE OF PARANÁ}

\begin{abstract}
Poultry farming is an expanding and representative sector for the Brazilian economy. In the State of Paraná (the largest producer and exporter of chicken meat in the country), the agribusiness system is more prominent, accounting for $11 \%$ of the gross value of agribusiness production. This system is also the largest generator of employment and income of the state of Paraná agribusiness, contributing to the significant increase of the state economy. In addition, in the agribusiness sectors, poultry farming is the one that has the greatest potential for job creation since it requires a lot of manpower for production and industrialization. In this scenario, as a central objective, this study objective to investigate the socioeconomic impacts of the poultry activity for broiler chicken producers in the Western region of state of Parana, as well as to identify the profile and characteristics of these subjects. Therefore, this qualitative study, reflects the results of a questionnaire applied locally to 133 poultry farmers of this region. The main results indicate that the activity is governed contractually between producers and agroindustries by the poultry integration system and composed by the predominance of producers with small properties. They are generally satisfied with both profitability and the guarantee of the return on investment made on their properties. In general, the results point to a scenario favorable to poultry farming in the region studied, evaluated positively by the agents involved.
\end{abstract}

Keywords: Agribusiness. Poultry farming. Agroindustrial system.

\footnotetext{
${ }^{1}$ Doutora em Desenvolvimento Regional e Agronegócio pela Universidade Estadual do Oeste do Paraná (Unioeste). Professora da Universidade Estadual do Oeste do Paraná (Unioeste). ivadcielo@hotmail.com

${ }^{2}$ Doutor em Engenharia de Produção pela Universidade Federal de Santa Catarina (UFSC). Professor da Universidade Estadual do Oeste do Paraná (Unioeste). wrochajr2000@gmail.com

${ }^{3}$ Doutoranda em Educação na Universidade Estadual de Maringá (UEM). Mestre em Ciências Ambientais pela Universidade Estadual do Oeste do Paraná (Unioeste). Professora da Universidade Estadual do Oeste do Paraná (Unioeste). fernandacsanches@gmail.com
} 
O agronegócio no Brasil é responsável por grande parte do desenvolvimento econômico do país. O setor apresenta um papel fundamental na balança comercial brasileira, além de ser um grande gerador de emprego e renda (UBABEF, 2013). Nesse cenário, aponta-se como destaque o setor da avicultura. A produção de frango de corte tem impressionado pelo dinamismo e pela competência conquistada nas últimas décadas. $O$ ganho de produtividade, associado à coordenação da cadeia avícola, possibilitou ao Brasil conquistar uma posição de destaque, ocupando a 1a colocação no ranking dos países exportadores de carne de frango e o 3 o como maior produtor mundial. Atualmente, a carne de frango brasileira é exportada para mais de 150 países (MAPA, 2014).

No contexto atual, o setor avícola é de fundamental importância para a economia brasileira. Dados da União Brasileira de Avicultura (UBABEF, 2013) e do Ministério da Agricultura, Pecuária e Abastecimento (MAPA, 2014), apontavam para a existência de aproximadamente $\mathbf{7 2 0}$ mil trabalhadores atuando nas indústrias de abate e processamento de frango, e outros 3,5 milhões ocupando vagas geradas direta e indiretamente pelo setor. Além disso, os dados mostram que o setor é responsável por uma movimentação financeira de cerca de $R \$ 36$ bilhões em negócios, com uma participação de 1,5\% no PIB brasileiro.

Esse dinamismo e desenvolvimento do setor resultam de uma série de fatores que contribuíram significativamente para que fossem alcançados os atuais ganhos de produtividade e competitividade. Para autores como Zilli (2003), MacDonald e Korb (2006) e Jesus Junior et al. (2007), entre esses fatores têm destaque as inovações tecnológicas na área de genética, de alimentação, de equipamentos e de manejo, aliadas à implantação do sistema de produção por meio de contratos de integração entre produtores rurais e agroindústria. Esse sistema de produção de frangos é conhecido no mercado e por pesquisadores da área como "sistema de integração", e será discutido com maior profundidade no decorrer deste texto.

Apesar de vários Estados brasileiros produzirem frango, segundo dados da Abpa (2017), a produção está concentrada nos Estados do Paraná, Santa Catarina, Rio Grande do Sul e São Paulo, os quais produziram, conjuntamente, em 2016, 72,96\% da produção doméstica, calculada em 12,9 mil toneladas. Entre os Estados produtores, o Paraná detém o título de maior produtor e exportador nacional, respondendo por $35,46 \%$ do total produzido nacionalmente e por $35,85 \%$ das exportações de carne de frango do país. A carne de frango produzida no Paraná é comercializada em mais de 130 países e injeta um valor superior a US\$ 2 bilhões anuais na economia do Estado (ABPA, 2017).

O sistema agroindustrial (SAG) avícola paranaense, de acordo com a Secretaria da Agricultura e do Abastecimento do Paraná - Seab-PR (2013), representa $11 \%$ do agronegócio do Estado. É também responsável pela geração de 660 mil empregos diretos e indiretos no Estado - cerca de 7\% da população paranaense, sendo a maior geradora de emprego e renda do agronegócio paranaense. Dos setores do agronegócio, a avicultura é o que tem mais potencial de geração de empregos, porque demanda muita mão de obra para produção e industrialização.

Inserida nesse contexto, a Mesorregião Oeste Paranaense (MROP) tem uma posição de destaque no cenário avícola estadual, responsável pelo abate de 33,7\% do total produzido no Estado (IPARDES, 2017). Além da presença de grandes empresas privadas e cooperativas agroindustriais de abate e processamento de frangos, a Mesorregião 
destaca-se pela produção de milho e soja, principais matérias-primas para fabricação de ração. Ademais, o agronegócio responde por mais da metade do PIB anual da MROP. $O$ setor é responsável por $\mathrm{R} \$ 12$ bilhões por ano, enquanto a soma de todas as riquezas dos 50 municípios que formam a MROP chega aos R\$ 23 bilhões (IPARDES, 2017).

Nesse contexto, considera-se relevante identificar a importância socioeconômica e conhecer o perfil dos avicultores vinculados contratualmente às agroindústrias da Mesorregião Oeste Paranaense. Isto posto, apresenta-se uma questão central a ser respondida: Quem são os produtores de frango de corte da MROP e qual a importância socioeconômica da atividade avícola a esses produtores? Para a obtenção de respostas a esse questionamento, este estudo tem como objetivo central investigar os impactos socioeconômicos refletidos no cotidiano dos produtores avícolas, bem como identificar a o perfil e características desses sujeitos.

Compreender esses aspectos é relevante, tendo em vista a importância econômica da atividade para a MROP e o fato de que os produtores são atores fundamentais para o êxito do sistema agroindustrial do frango de corte. A pesquisa também é proeminente para auxiliar no estabelecimento de políticas públicas mais afetivas para o setor.

Para atingir o objetivo proposto, o presente estudo está estruturado em cinco partes centrais. Após esta introdução, são tecidas considerações acerca do setor avícola brasileiro. A seguir, os procedimentos metodológicos aqui adotados são explicitados. $\mathrm{Na}$ sequência, apresenta-se os principais resultados encontrados. Para finalizar, expõe-se as considerações finais, sugestões para pesquisas futuras e as referências bibliográficas empregadas no estudo.

\section{O SETOR AVÍCOLA BRASILEIRO}

A agroindústria avícola brasileira tem merecido posição de destaque no cenário do agronegócio nacional e internacional, constituindo-se, dentro do complexo de carnes, a atividade mais dinâmica. Historicamente, o desenvolvimento dessa atividade, em escala comercial, surge com maior intensidade no final da década de 50 do século 20 nos Estados de São Paulo e Minas Gerais, a partir da importação dos Estados Unidos de linhagens híbridas de frango de corte (RIZZI, 1993).

Nos anos subsequentes, principalmente a partir de 1970, o complexo agroindustrial avícola de frango de corte, impulsionado pelas transformações no aparato produtivo da economia brasileira, passou por um processo de mudanças na base técnica de produção, modernização e consequente aumento no número de indústrias processadoras em diversos Estados, principalmente na Região Sul.

Assim, a atividade, antes praticamente restrita à Região Sudeste, desloca-se para o Sul do país, principalmente para o Estado de Santa Catarina, e começa uma nova fase de exponencial crescimento, modernização e expansão (BARCZSZ; LIMA FILHO, 2009).

Autores como Rizzi (1993) e Canaver et al. (1997) afirmam que a expansão das agroindústrias processadoras de carne de frango, sobretudo na Região Sul, foi viabilizada pela política agrícola, fortemente vinculada pelas condições de liquidez financeira internacional e pela política de crédito que subsidiou a instalação de frigoríficos e de 
aviários. Nesse mesmo período, intensificaram-se as importações de tecnologias genéticas e técnicas ambientais, sanitárias, nutricionais, de abate e de processamento, modificando, assim, o sistema produtivo da avicultura.

Aliado a isso, o setor foi favorecido por contribuições advindas do avanço tecnológico, a exemplo da biotecnologia, microeletrônica e automação. A evolução tecnológica na avicultura resultou, sobretudo, em ganhos de eficiência na produtividade, propiciando melhorias na conversão alimentar ${ }^{4}$ e progressiva redução no tempo necessário para o abate. Esse ganho de eficiência pode ser comprovado pelos dados do Quadro 1.

Quadro 1 - Evolução média dos coeficientes de produção de frango de corte no Brasil

\begin{tabular}{|c|c|c|c|}
\hline Ano & Peso frango vivo (g) & Conversão alimentar & Idade de abate - dias \\
\hline $\mathbf{1 9 3 0}$ & 1500 & 3,5 & 105 dias \\
\hline $\mathbf{1 9 4 0}$ & 1550 & 3,00 & 98 dias \\
\hline $\mathbf{1 9 5 0}$ & 1580 & 2,50 & 70 dias \\
\hline $\mathbf{1 9 6 0}$ & 1600 & 2,25 & 56 dias \\
\hline $\mathbf{1 9 7 0}$ & 1700 & 2,15 & 49 dias \\
\hline $\mathbf{1 9 8 0}$ & 1800 & 2,05 & 49 dias \\
\hline $\mathbf{1 9 8 5}$ & 1900 & 2,00 & 49 dias \\
\hline $\mathbf{1 9 9 0}$ & 1940 & 2,00 & 47 dias \\
\hline $\mathbf{1 9 9 5}$ & 2050 & 1,98 & 45 dias \\
\hline $\mathbf{2 0 0 0}$ & 2250 & 1,88 & 43 dias \\
\hline $\mathbf{2 0 0 5}$ & 2300 & 1,82 & 42 dias \\
\hline $\mathbf{2 0 1 0}$ & 2300 & 1,76 & 41 dias \\
\hline
\end{tabular}

Fonte: Elaborado pelos autores a partir dos dados da UBABEF (2011).

Embora os dados disponíveis datem de 2011 e refiram-se à média nacional, cabe destacar que, em 2018, na avicultura da MROP, há registros de conversão alimentar na ordem de 1,69, batendo recorde nos índices de eficiência nacional para o no setor (AGROEMDIA, 2018). É importante destacar, entretanto, que, dependendo da destinação da carne, tanto o peso quanto o tempo médio de engorda podem sofrer modificações. De acordo com Salviano (2011, p. 38), “algumas agroindústrias estão produzindo para mercados altamente exigentes em termos de qualidade do produto e faixa específica de peso que acarreta conversões alimentares variáveis".

Além dos fatores tecnológicos, as alterações na forma de produção, passando de processo produtivo autônomo para integração entre agroindústrias e produtores, foram fundamentais para o desenvolvimento da atividade no Brasil. Para autores como Rizzi (2004), Pereira, Melo e Santos (2007) e Salviano (2011), essa estratégia de integração possibilitou às empresas ganhos de eficiência obtidos por meio da qualidade em termos de padronização da matéria-prima, redução de custos industriais nas operações de

\footnotetext{
${ }^{4}$ Conversão alimentar é, por definição, o consumo de ração do animal em um período de tempo, dividido pelo seu ganho de peso também em um período de tempo.
} 
abate, padronização de carcaças, abastecimento constante, dentre outras. O sistema de integração permitiu, ainda, a rápida transferência tecnológica, principalmente mediante os serviços de assistência técnica e consequente melhoria nos níveis de produtividade.

Se, por um lado, o avanço tecnológico e as mudanças no processo produtivo foram responsáveis pelo aumento da produção de frangos de corte, por outro o acelerado processo de urbanização em razão dos processos migratórios rurais-urbanos e da inserção com maior intensidade da mulher no mercado de trabalho, ampliaram as bases industriais de bens de consumo e, consequentemente, o tamanho do mercado. Assim, o consumo de carne de frango evoluiu rapidamente e, em poucas décadas, passou a ser a principal fonte proteica da população (RIZZI, 1993). O crescimento e a evolução do consumo de carne de frango no Brasil podem ser mais bem visualizados no Gráfico 1.

Gráfico 1 - Evolução do consumo brasileiro de carne de frango (Kg. hab. 2017)

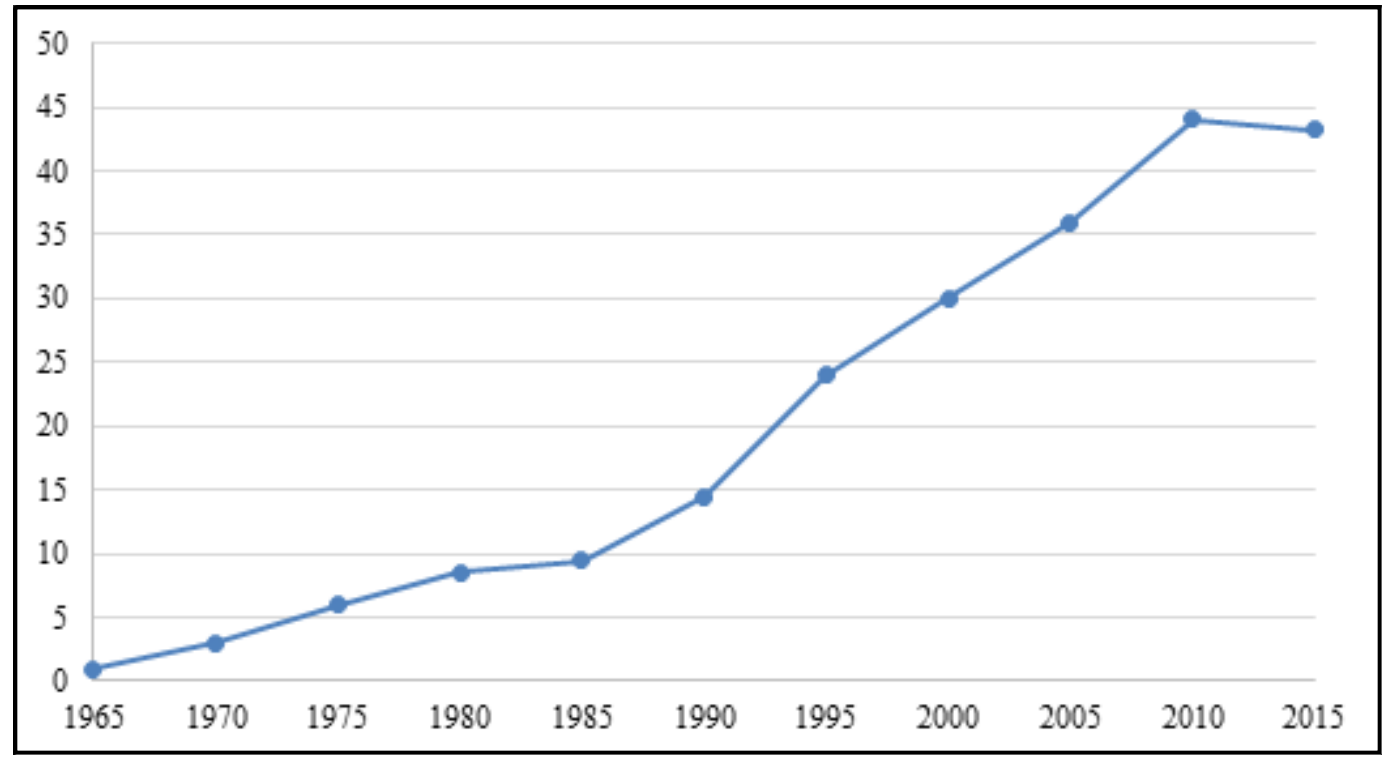

Fonte: Elaborado pelos autores a partir dos dados da Embrapa (2003), UBABEF (2014) e ABPA (2017).

Desde o início da produção em escala do frango de corte, na década de 60, ocorreu significativo crescimento do consumo da carne de frango no país. Ao longo do período, no entanto, percebe-se ligeira desaceleração de consumo na primeira parte da década de 80. De acordo com Wilkinson (1993), esta retração foi resultado da forte concorrência das exportações subsidiadas dos EUA e da Comunidade Econômica Europeia (CEE), atual União Europeia (EU), aliada à recessão econômica do país, afetando o desempenho do mercado interno e, por consequência, do consumo per capita. Não se tratou, porém, apenas de retração de consumo interno, mas de redução de produção, consumo interno e exportação.

A partir de 1985, o consumo de carne de frango apresentou um exponencial crescimento, impulsionado, principalmente, pelas mudanças no estilo de vida e de hábitos alimentares do brasileiro, passando a utilizar cada vez mais a carne de frango como base da sua alimentação. Para Lima Filho et al. (2005), o fator saúde é um dos elementos considerados determinantes na compra da carne de frango, uma vez que, ao longo dos anos, os consumidores foram convencidos, por intermédio de inúmeras estratégias de marketing, que a carne branca de frango é de melhor qualidade, comparativamente às carnes bovina e suína. 
A tendência de elevação do consumo de carne de frango continuou ao longo da década de 90 e nos anos 2000, superando, em 2006, a carne bovina, mais consumida no país até aquele ano. Em 2013, o consumo médio por habitante de carne bovina foi de $36,2 \mathrm{~kg}$, contra 41,8 kg de carne de frango (MAPA, 2014).

Paralelamente ao crescimento do consumo, as características do mercado de aves também vêm mudando. No início da década de 60 a maior parte da produção era composta de frango "standard", vendido a preços baixos sem muitos requisitos em relação à qualidade. Com as alterações nos hábitos alimentares e nos padrões culturais da população, as indústrias passaram a focar ações em relação à qualidade, adaptando-se às necessidades dos consumidores.

Nesse sentido, intensificou-se a produção e comercialização de produtos certificados de origem regional controlada, além de produtos com maior valor agregado a exemplo dos cortes diferenciados de frangos temperados, embutidos e defumados. Tais estratégias utilizadas, além de ampliar a oferta e atender às demandas do novo público consumidor, alavancaram ainda mais o setor, que já estava em franco desenvolvimento (RIZZI, 1993).

Atualmente, a avicultura brasileira oferece uma gama de produtos destinados para as mais distintas faixas de renda, atendendo às necessidades de praticidade e conveniência não somente para o mercado interno, mas exportando parte de sua produção para distintos países.

A importância da avicultura, no entanto, vai além da produção de proteína animal. É um dos setores que mais emprega no país, contribuindo para o crescimento significativo das contribuições do agronegócio para a economia brasileira. Considerando sua importância econômica, o setor avícola tornou-se essencial em Regiões como Sudeste e, principalmente, Sul, onde está concentrada a maior parte da produção nacional.

Em Estados como Paraná e Santa Catarina, primeiro e segundo maiores produtores de carne de frango no país, respectivamente, a avicultura assume papel de maior relevância. A importância do setor reside não apenas na geração direta de empregos e renda, mas na economia indireta gerada pelo setor, como na produção agrícola, empreendimentos rurais, logística, máquinas e equipamentos, alimentação animal, varejo entre outras (IPARDES, 2002).

De acordo com Rizzi (1993), a concentração da atividade na Região Sul, e consequente instalação de inúmeras agroindústrias, foi impulsionada pelo processo de modernização agrícola acorrida a partir de 1970 e pelas próprias características da região como polo de atração de capitais tanto nacionais quanto estrangeiros. Além disso, empresas que possuíam negócios na produção de suínos e de cereais, principalmente na Região Sul, passam a atuar também no setor avícola, deslocando a atividade, inicialmente introduzida na região Sudeste, para o Sul do Brasil.

O Gráfico 2 apresenta a atual distribuição da produção avícola brasileira por Unidade Federativa, bem como a evolução e a participação ao longo dos últimos anos. 
Gráfico 2 - Evolução na participação dos Estados nos abates de frango - Brasil - 2003-2017

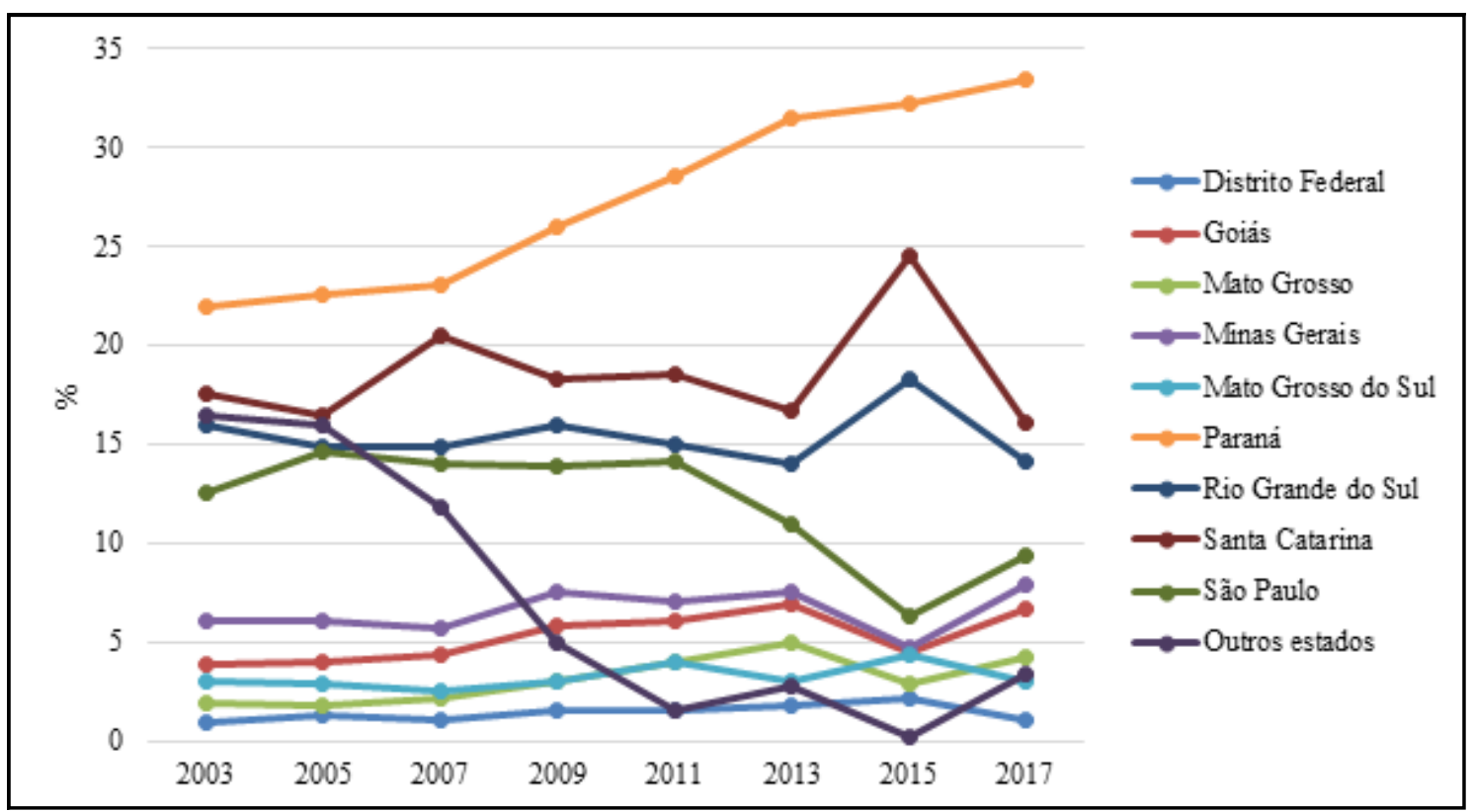

Fonte: Elaborado pelos autores a partir dos dados da ABPA (2017).

De acordo com o Gráfico 2, é perceptível a evolução na participação dos Estados no abate de frango, denotando a supremacia da capacidade produtiva no setor de frango de corte do Paraná. O Estado ocupa, ao longo da década, o posto de maior produtor de frango, distanciando-se dos demais Estados produtores, como Santa Catarina, Rio Grande do Sul e São Paulo. Durante o período avaliado, a atividade apresentou significativo crescimento, passando de $21,9 \%$ para mais de $30 \%$ de participação na produção total do país. Esse crescimento é atribuído, principalmente, pela oferta de grãos no Estado, aliada ao sistema integrado de produção.

Por outro lado, Estados com tradição na avicultura de corte, a exemplo de Santa Catarina, Rio Grande do Sul e São Paulo, não obtiveram o mesmo desempenho, mantendo os índices de produção nos mesmos patamares ao longo da década. A participação dos Estados no abate de frango no ano de 2017 é apresentada na Figura 1.

Em relação à distribuição da produção avícola nos distintos Estados brasileiros, destaca-se a concentração da atividade na Região Sul, líder histórica na produção nacional e responsável por 63,63\% da produção total de aves abatidas em 2017. Embora a atividade tenha expandido-se para outras regiões, a dimensão que assumiu na Região Sul dificilmente será obtida nas demais regiões, em virtude do encadeamento e estruturação do SAG avícola estabelecido nestes Estados. Lima (1984) já chamava a atenção para o processo de concentração na Região Sul ainda nos seus primórdios da expansão da avicultura brasileira, e apregoava que dificilmente em outras Regiões do Brasil haveria atividades no mesmo nível de desempenho.

A justificativa, do ponto de vista do autor, baseava-se em fatores como características culturais da população, estrutura fundiária dos Estados, embasada no processo de emigração estrangeira, concentração da produção dos insumos básicos da avicultura (soja e milho), como fatores que propiciam a performance positiva do setor. Em relação à produção dos insumos básicos, o autor destaca que a proximidade da atividade avíco- 
la aos centros de produção de grãos implica menores custos globais e melhor desempenho do setor, mesmo que se tenha de transportar posteriormente o produto final para um mercado consumidor distante (LIMA, 1984).

Figura 1 - Participação dos Estados no abate de frango em 2017 (\%)

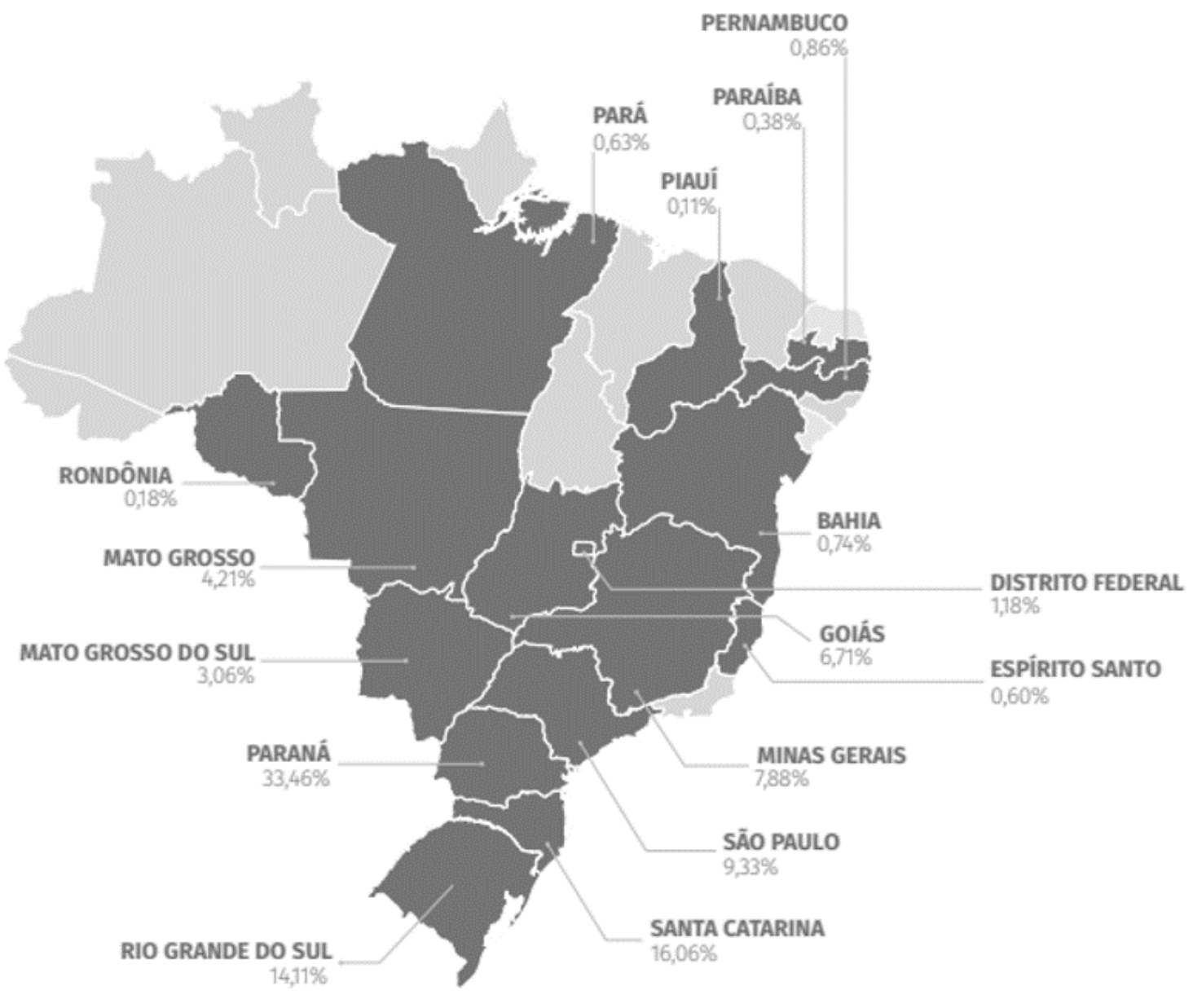

Fonte: ABPA (2017).

\section{PROCEDIMENTOS METODOLÓGICOS}

Este estudo objetiva analisar características do sistema de produção de frango de corte na Mesorregião Oeste Paranaense. Especificamente, busca-se compreender a importância socioeconômica da avicultura para os produtores de frango da região em estudo. Nesse sentido, e, no intuito de buscar respostas à questão de pesquisa, a abordagem qualitativa fundamenta o arcabouço metodológico predominante no estudo, tanto em razão da natureza do problema quanto pelo grau de aprofundamento desejado.

Para tanto, as ideias centrais da pesquisa são fundamentadas em Richardson (1999), o qual cita que o recurso qualitativo se apresenta como forma adequada para a compreensão dos fenômenos sociais, justo porque se fundamenta na análise de diferentes perspectivas e nas reflexões dos pesquisadores a respeito de sua investigação como parte do processo de produção de conhecimento. 
Quanto aos objetivos, a pesquisa pode ser caracterizada como de cunho exploratório, descritivo e explicativo. Inicialmente, o estudo desenvolve-se por meio de uma pesquisa exploratória baseada em dados secundários, a exemplo de bibliografias acerca do tema em questão, relatórios técnicos e demais documentos pertinentes. Essa etapa buscou conhecer o histórico e a trajetória de agroindústrias avícolas e seus sistemas de integração na região de investigação. Posteriormente, com o intuito de elucidar as especificidades da investigação proposta e, consequentemente, aumentar o conhecimento acerca do objeto de estudo, realizou-se uma pesquisa de caráter descritivo. Gil (2009, p. 42) menciona que a pesquisa descritiva, "têm como objetivo primordial a descrição das características de determinadas populações ou fenômenos ou, então, o estabelecimento de relações entre variáveis".

O universo da pesquisa foi composto por $3.013^{5}$ estabelecimentos produtores de frango de corte instalados na Mesorregião Oeste Paranaense. Para a delimitação da amostra, fez-se uso da amostragem estratificada não proporcional, uma vez que foram selecionados elementos em cada subgrupo da população, obtendo uma amostra com distribuição equilibrada de produtores de frangos integrados a cada uma das sete agroindústrias. Em relação a essa forma de amostragem, Gil (2009, p. 123) postula que "há situações em que esse procedimento é o mais adequado, particularmente naquela em que se tem interesse na comparação entre os vários estratos". Cabe ressaltar que essa forma amostral foi utilizada em razão do objetivo central do presente artigo.

Considerando o caráter qualitativo da pesquisa, o fechamento amostral ocorreu pelo processo intitulado saturação teórica, que suspende a inclusão de novos participantes quando os dados obtidos passam a apresentar, na avaliação do pesquisador, uma certa redundância ou repetição, não mais contribuindo significativamente ao aperfeiçoamento da reflexão teórica fundamentada nos dados que estão sendo coletados. Ou seja, as informações fornecidas pelos novos participantes da pesquisa pouco acrescentariam ao material já obtido (FONTANELLA; RICAS; TURATO, 2008).

Assim sendo, a quantidade de entrevistas com os produtores não foi definida com exatidão a priori, mas, sim, estabelecida à medida que a pesquisa foi se desenvolvendo. Ao final, foram obtidas 133 entrevistas com avicultores. Estes foram investigados acerca do sistema de integração avícola do qual fazem parte. Para tanto, aplicou-se um roteiro de questões realizadas in loco nas propriedades localizadas em distintos municípios da Mesorregião Oeste do Paraná. O questionário buscou delimitar o perfil dos produtores a partir das seguintes dimensões: faixa etária; gênero; grau de instrução; mão de obra e tamanho das propriedades; capacidade produtiva e quantidade de granjas. Ademais, investigou questões relacionadas à importância socioeconômica da avicultura para os atores envolvidos por meio das dimensões: motivações que impulsionaram o investimento na área; tempo de atuação na avicultura; forma de custeio para instalação das granjas e, por fim, o apontamento de existência de políticas públicas de fomento à atividade.

Os dados coletados foram interpretados utilizando-se a análise de conteúdo. Tal proposição metodológica justifica-se porque a análise de conteúdo conduz à descrição objetiva e sistemática do conteúdo de mensagem, permitindo a sua manipulação tanto do

${ }^{5}$ Quantitativo obtido com as agroindústrias produtoras e processadoras de aves da Mesorregião Oeste do Paraná. 
teor quanto de expressões deste conteúdo. Nesse enfoque, evidenciam-se, assim, indicadores que permitam inferir sobre uma outra realidade que não da mensagem (RICHARDSON, 1999; BARDIN, 2004). Por fim, cabe destacar que esta pesquisa é um recorte de um estudo mais amplo, desenvolvido como tese doutoral de um dos autores deste artigo.

\section{RESULTADOS E DISCUSSÕES}

\section{Perfil dos Produtores de Frango de Corte Vinculados ao Sistema de Integração Avícola}

A avicultura é atividade de destaque na Mesorregião Oeste do Paraná. O setor é responsável pelo equivalente a $R \$ 4,2$ bilhões do $\mathrm{PIB}$, ou seja, $18,2 \%$ do total das riquezas produzidas e $35 \%$ do total do agronegócio regional. Ademais, na MROP estão instaladas 8 grandes agroindústrias de abate e processamento de aves, responsáveis pelo abate de $32,57 \%$ do total de frangos produzidos no Paraná (IPARDES, 2017).

Para dar conta dessa produção, as 8 agroindústrias instaladas possuem contratos de parceria para a produção de aves com 3.013 produtores, que detém um total de $4.908^{6}$ granjas de frangos de corte instaladas nos distintos municípios da MROP. Assim, para uma análise sistêmica da integração avícola, considerada como um modelo exitoso para a produção de aves, faz-se necessário conhecer a percepção daqueles que estão em sua base, ou seja, os produtores de aves. Dessa forma, o presente estudo dedica-se a apresentar as opiniões dos 133 produtores investigados acerca do sistema de integração avícola do qual fazem parte.

Os produtores avícolas investigados na pesquisa estão espacialmente distribuídos em distintos municípios da Mesorregião Oeste Paranaense, como pode ser observado na Figura 2 , cuja coloração apresenta com quais agroindústrias se relacionam contratualmente.

Figura 2 - Quantitativo de entrevistas realizadas por município e por agroindústria

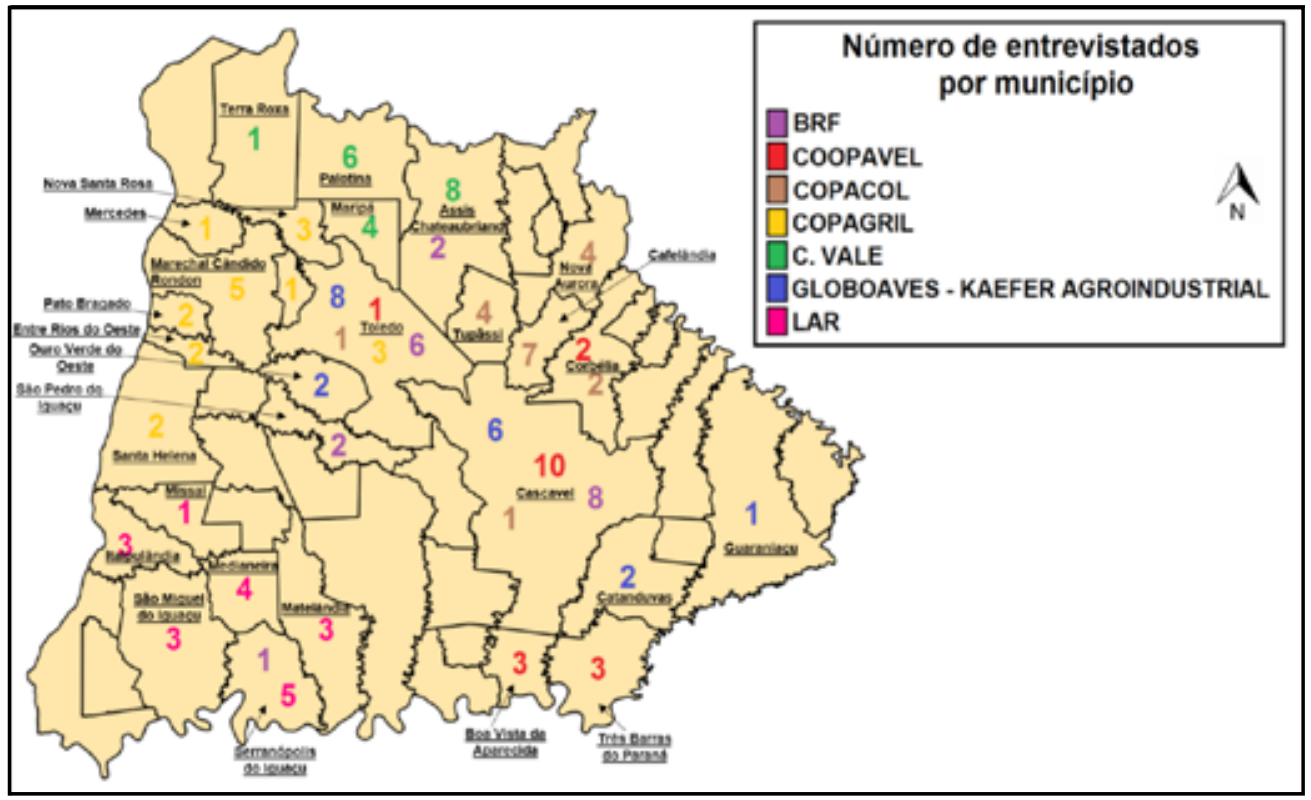

Fonte: Dados da pesquisa.

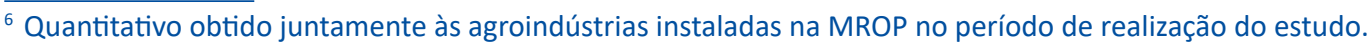


O município de Cascavel detém o maior número de produtores entrevistados, justamente por contar com duas agroindústrias instaladas. Constatou-se, entretanto, a presença de diversos produtores que residem nesse município, mas que produzem aves para empresas com sede em outros municípios. Esse fato denota a existência de flexibilidade das agroindústrias em relação à delimitação da fronteira territorial de atuação.

Muito embora a redução da área de atuação é uma política explicitada nos discursos dos gestores das agroindústrias, a atividade ainda é desenvolvida em um número significativo de municípios e, em muitos casos, distantes das agroindústrias. Essa distância geográfica gera custos em logística e dificuldades para a concentração da atividade. Por outro lado, um maior distanciamento entre as granjas possibilita mais controle em relação à biossegurança, reduzindo o risco de contaminação entre granjas e aumentando a qualidade sanitária dos plantéis. Ou seja, em uma eventual epidemia, este distanciamento pode gerar uma externalidade positiva.

Em relação ao perfil do produtor, o primeiro aspecto considerado está relacionado ao gênero dos avicultores. Contatou-se que a produção de aves é uma atividade mais frequentemente desenvolvida por homens, compreendendo $77,45 \%$ dos respondentes. Já a presença feminina representa apenas $22,55 \%$.

Cabe destacar, no entanto, que a participação das mulheres nessa etapa da produção tende a um crescimento significativo, impulsionado, por um lado, pelos avanços tecnológicos que facilitaram o trabalho nas granjas e, por outro, pela própria natureza da atividade. $\mathrm{O}$ cuidado com as aves em granjas automatizadas demanda mais aspectos subjetivos, características físicas e comportamentais mais comuns e atinentes às mulheres, do que da força física.

A pesquisa revelou ainda que as mulheres estão mais satisfeitas com a atividade e conseguem obter melhores resultados nos lotes produzidos, comparativamente aos homens. Cientes dessa nova realidade positiva, as agroindústrias têm desenvolvido ações visando a incentivar a participação feminina na atividade não apenas como gestoras dos negócios, mas como mão de obra responsável pelo manejo das granjas.

Além das questões de gênero, a pesquisa investigou também a faixa etária dos produtores de frango da MROP. Dados detalhados da idade dos produtores podem ser visualizados no Gráfico 3.

Gráfico 3 - Faixa etária dos produtores de frango da MROP

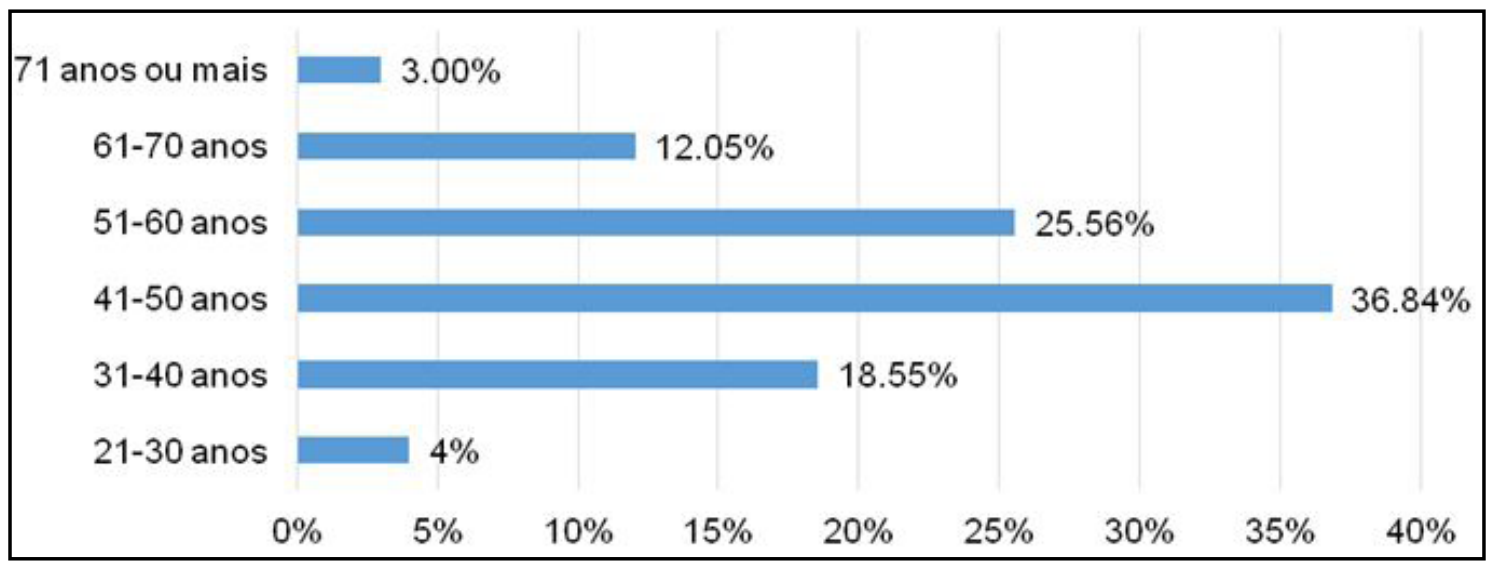

Fonte: Dados da pesquisa. 
A faixa etária predominante entre os produtores entrevistados situa-se entre os 41 e 50 anos e, portanto, é formada por pessoas com capacidade produtiva para o desempenho da função. Chama a atenção, porém, o fato da pouca inserção de jovens na atividade. Apenas 4\% dos entrevistados têm menos que 30 anos. Em contrapartida, $15,05 \%$ possuem idade superior a 60 anos.

Esses dados comprovam que a sucessão geracional nesta atividade pode não estar acompanhando as exigências de aumento de produção de matéria-prima para as agroindústrias. Assim, o envelhecimento da população, aliado à baixa inserção dos jovens na atividade avícola, pode se constituir em um dos gargalos da avicultura moderna.

Por outro lado, os avanços tecnológicos no sistema de produção de aves e os novos paradigmas de gestão difundidos nas agroindústrias do setor, têm promovido mudanças positivas no perfil do produtor de aves da MROP. Para além da imagem simples de homem do campo, o avicultor apresenta-se como um empresário rural que investe constantemente em novas tecnologias e em desenvolvimento profissional. 0 perfil dos avicultores aponta para profissionais especializados, com visão empresarial e com níveis educacionais superiores à média nacional e estadual para populações urbanas e rurais. Isso pode ser visualizado no Gráfico 4.

Gráfico 4 - Grau de instrução dos produtores avícolas comparativamente à população urbana e rural brasileira e paranaense

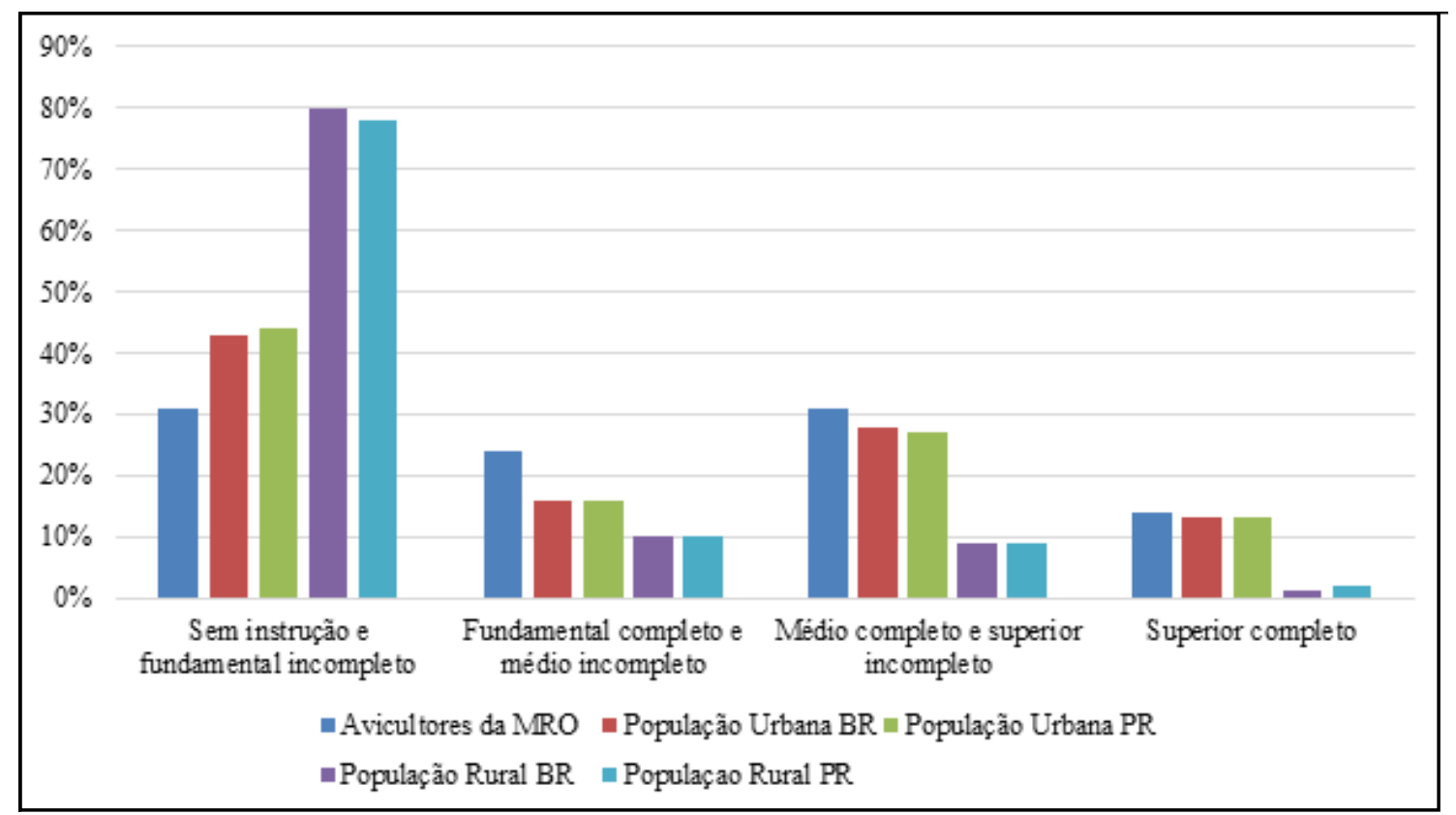

Fonte: ATLAS BRASIL (2019); dados da pesquisa de campo.

Os produtores investigados possuem melhores níveis de escolaridade, tanto comparativamente à população urbana quanto rural do Brasil e do Estado do Paraná. Se, entretanto, comparados a apenas dados da população rural, as diferenças ficam ainda mais evidentes. Observa-se, por exemplo, que $79,60 \%$ da população rural acima de 25 anos é composta por pessoas sem instrução e com Ensino Fundamental incompleto, enquanto para os avicultores da MROP esse índice é de apenas 30,93\%. 
Há que se destacar também que o percentual de produtores com Ensino Superior completo é maior do que aquele apresentado pela população residente na área urbana (14,43\% e $12,90 \%$ respectivamente), e que 3,75\% dos produtores possuem especialização lato sensu. Ou seja, o percentual de produtores com especialização na MROP é superior à média nacional da população rural que concluiu a Graduação.

Esses índices de qualificação implicam vantagens competitivas do SAG avícola da MROP ante a outras regiões do Estado e do Brasil. Pessoas com grau de instrução mais elevado possuem maior capacidade de absorver as informações, de acessar as novas tecnologias e, por consequência, obter maior produtividade em sua área de atuação.

Outra característica peculiar do sistema de integração na MROP diz respeito ao tamanho das propriedades rurais em que a atividade avícola é desenvolvida, sendo, em sua maioria (63\%), propriedades rurais de até 20 ha. A pesquisa revela também que a atividade avícola é desenvolvida, prioritariamente, a partir do uso de mão de obra familiar, realidade presente em $71 \%$ das propriedades investigadas. Em $29 \%$ das propriedades, o trabalho de cuidados das aves é desenvolvido utilizando-se mão de obra contratada. É relevante mencionar, no entanto, que, mesmo com a contratação de funcionários, em muitos casos o trabalho é desenvolvido de forma conjunta, tanto com o uso de mão de obra familiar quanto com de funcionários.

Outro dado levantado pela pesquisa refere-se ao quantitativo de granjas por propriedades e a capacidade de alojamento dessas granjas.

\section{Gráfico 6 - Quantitativo de granjas por propriedade e capacidade de alojamento por granjas}
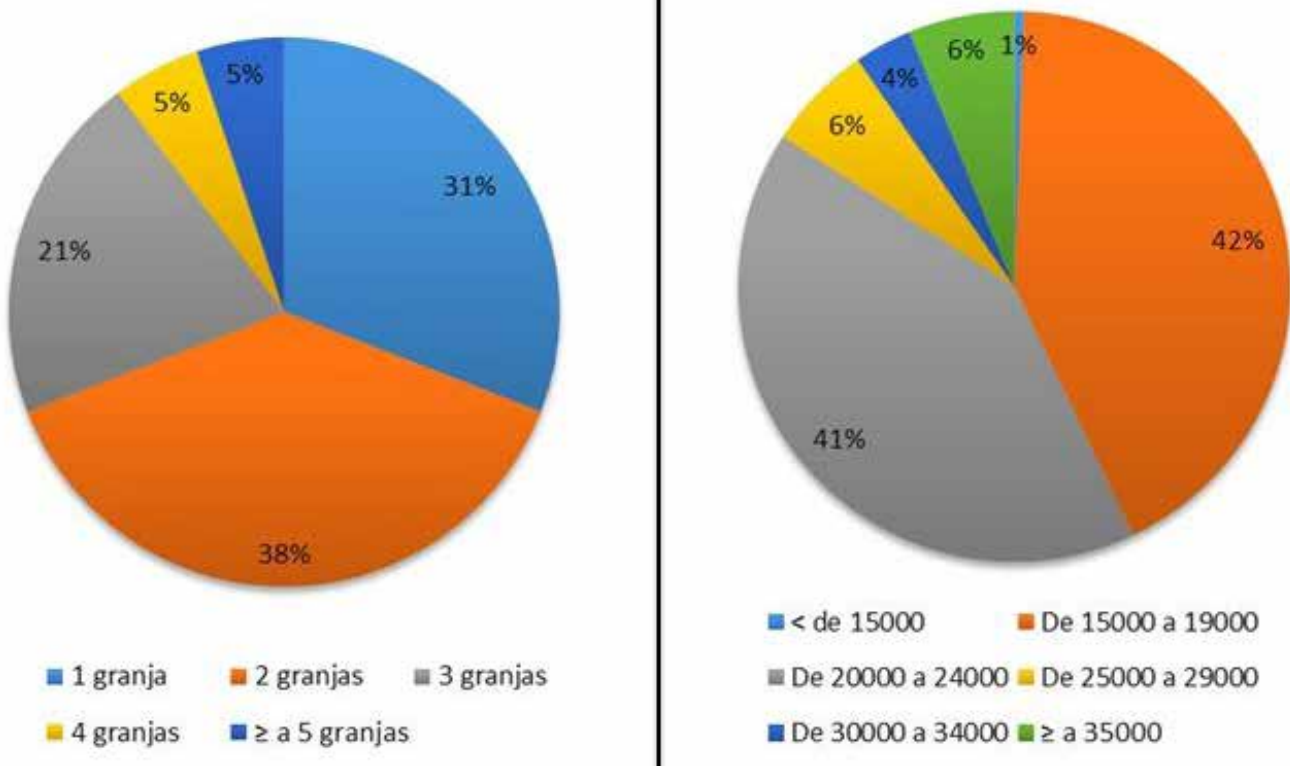

Fonte: Dados da pesquisa.

Os dados apresentados no Gráfico 6 corroboram as informações já mencionadas referentes ao delineamento do perfil da atividade avícola, isto é, uma atividade desenvolvida por pequenos produtores rurais. Isso porque $69 \%$ dos produtores possuem até duas granjas em suas propriedades, $21 \%$ possuem três granjas e apenas $10 \%$ dos entrevistados possuem quatro granjas ou mais em suas propriedades. Paralelamente ao quantitativo de granjas está sua capacidade produtiva. Os dados da pesquisa mostram 
também que $42 \%$ das granjas são de pequeno porte, com capacidade para alojar de 15.000 a 19.000 aves e que apenas $9 \%$ das granjas têm capacidade de alojar um número igual ou superior a 30.000 aves.

Ponderando sobre o perfil delineado para o avicultor da MROP, é possível inferir que assumir a tendência de concentração de atividade em um número menor de propriedades, com granjas cada vez mais automatizadas e com maior capacidade de produção, coloca à margem do sistema a maior parcela dos atuais produtores. Assim sendo, os aspectos apresentados evidenciam que a avicultura é uma atividade predominantemente familiar e desenvolvida por pequenos produtores rurais, portanto com reduzida capacidade para investir em modernização das granjas, como requer o novo sistema desejado pelas agroindústrias.

\section{Importância Socioeconômica da Avicultura de Corte para os Produtores}

É relevante o fato apontado na literatura existente de que a avicultura de corte se constitui numa importante atividade econômica para a MROP, tanto em relação ao volume de carne produzido quanto ao número de empregos diretos e indiretos gerados ao longo de todo o SAG. Para o produtor de aves, entretanto, os ganhos vão além da geração de empregos ou mesmo do autoemprego e da permanência da família no campo. Representam, para $60 \%$ dos produtores entrevistados, a principal fonte de renda da propriedade rural. Para 40\%, a atividade apresenta-se como fonte de renda secundária na propriedade, sendo desenvolvida em consonância com a produção de grãos (principal fonte de renda para $79,85 \%$ dessas propriedades), produção de leite, de suínos e peixes. Para os demais, $11,36 \%$ dessa parcela, a principal fonte de renda advém de atividades não agropecuárias.

Quanto aos motivos que impulsionaram os produtores agrícolas a investir na avicultura, a possibilidade de uma renda extra às atividades agropecuárias desenvolvidas aparece como principal propulsor para $57,42 \%$ dos produtores. As principais motivações elencadas pelos produtores para a instalação dos aviários estão expostas no Quadro 2.

Quadro 2 - Principais motivos para instalação das granjas de aves de corte

\begin{tabular}{|l|c|c|}
\hline \multirow{2}{*}{ Principais motivos para instalação das granjas } & \multicolumn{2}{|c|}{$\begin{array}{c}\text { Ocorrência nas entrevis- } \\
\text { tas realizadas }\end{array}$} \\
\cline { 2 - 3 } & $\mathrm{N} 0$ & $\%$ \\
\hline Renda extra & 76 & 57,42 \\
\hline Viabilizar a pequena propriedade & 18 & 13,53 \\
\hline Diversificação da propriedade & 17 & 12,78 \\
\hline Renda em menor tempo & 12 & 9,02 \\
\hline Renda mais estável & 12 & 9,02 \\
\hline Segurança maior de renda em relação à lavoura & 11 & 8,27 \\
\hline Utilizar a cama de aviário como adubo para a lavoura & 8 & 6,01 \\
\hline Gosto pela atividade & 7 & 5,26 \\
\hline Manter a família no campo & 6 & 4,51 \\
\hline Aposentadoria & 5 & 3,75 \\
\hline Compra da propriedade com a granja já instalada & 3 & 2,25 \\
\hline Herança & 2 & 1,03 \\
\hline
\end{tabular}

Fonte: Dados da pesquisa. 
Além da possibilidade de uma renda extra às atividades agropecuárias desempenhadas, a avicultura representa uma forma de viabilizar a pequena propriedade e diversificar a produção, permitindo ao produtor condições de obter renda em menor espaço de tempo, comparativamente às demais atividades agropecuárias. Com a avicultura, em média, o produtor tem entrada de recursos financeiros para gerir a propriedade a cada dois meses, tempo significativamente menor em relação à suinocultura (seis meses) e à produção de soja e milho, com safras anuais.

Ainda, é conveniente destacar que a opção do produtor pela avicultura pode representar uma possibilidade de renda mais estável e maior segurança em relação à produtividade, principalmente se comparada à produção de grãos. Na avicultura, os resultados estão diretamente relacionados às boas práticas de manejo e demais variáveis passíveis de controle, enquanto na produção de grãos esses resultados sofrem interferência de aspectos que fogem do controle do produtor, a exemplo das intempéries climáticas. Para uma parcela dos produtores entrevistados, entretanto, a atividade não possibilita ganhos diretos. Para eles, a motivação para ingressar no setor deu-se em razão da possibilidade de utilizar a cama dos aviários como adubo para o cultivo de diversas culturas, principalmente para a produção de grãos. Dentre esses produtores, estão aqueles com maiores áreas cultiváveis e que não têm na avicultura a principal fonte de renda da propriedade rural.

Independentemente dos objetivos para o ingresso na atividade avícola, a possibilidade de financiamentos para instalação dos galpões e do aparato tecnológico necessário ao funcionamento das granjas, é um dos fatores que impacta positivamente na decisão de investir na avicultura. A pesquisa mostra que, dos 133 produtores entrevistados, $88 \%$ recorreram a financiamentos para a instalação das granjas. Apenas $12 \%$, portanto, efetivaram suas granjas com recursos próprios.

Dado o perfil do produtor de aves, composto, em sua maioria (92\%), por pequenos produtores e o montante necessário para a construção das granjas (valor médio de $\mathrm{R} \$ 500.000,00),{ }^{7}$ o elevado índice de produtores que recorrem a financiamentos para o ingresso na atividade é plenamente justificável. É interessante destacar, todavia, que a obtenção de financiamentos a esses pequenos produtores realiza-se mediante parcerias entre agentes financeiros, integradoras e produtores, que possibilitam a contratação de recursos com flexibilidade no pagamento e menor exigência de garantias por parte do produtor.

O modelo de parceria para financiamento, adotado no setor avícola, é diretamente intermediado pelas empresas integradoras, que se responsabilizam pela elaboração dos projetos de viabilidade e agilizam a parte documental para os produtores, além de auxiliá-los na escolha da linha de crédito mais viável de acordo com sua capacidade de pagamento.

Para a construção das granjas, as linhas de crédito do Banco Nacional de Desenvolvimento Econômico e Social (BNDES) são as mais buscadas pelos produtores de frango. Além do BNDES, o Banco Regional de Desenvolvimento do Extremo Sul (BRDE) também possui linhas de crédito específicas para a expansão da atividade avícola. O BNDES e o

${ }^{7}$ Valor médio cotado no mês de novembro de 2016. 
BRDE, no entanto, não financiam diretamente ao produtor, e a liberação dos recursos é realizada por intermédio de um agente financeiro (banco ou cooperativa de crédito). $\mathrm{Na}$ MROP, o Sicredi é o agente financeiro que mais realiza essas operações (57\%), seguido pelo Banco do Brasil, responsável por $20 \%$ dos financiamentos.

Outras instituições financeiras também foram apontadas como agentes responsáveis pelos financiamentos, a exemplo do Banco Itaú, Unibanco e Real. Além dessas instituições financeiras, programas do governo estadual, como o "Panela Cheia", fomentaram a construção de aviários, principalmente na década de 90 . Esse programa foi responsável pelo financiamento das granjas de $8 \%$ dos entrevistados.

As facilidades de acesso ao crédito e as formas e prazos flexíveis de pagamento dos financiamentos, não se restringem à construção de novas granjas, mas a reformas e atualização de padrão tecnológico. Essa possibilidade de obtenção de recursos para melhorias nas granjas impulsiona os produtores para investir e, por consequência, manter-se na atividade, mesmo em período de crises no setor e baixa lucratividade, 0 que pode ser visualizado no Gráfico 7.

Gráfico 7 - Tempo de atuação dos produtores de frango da MROP

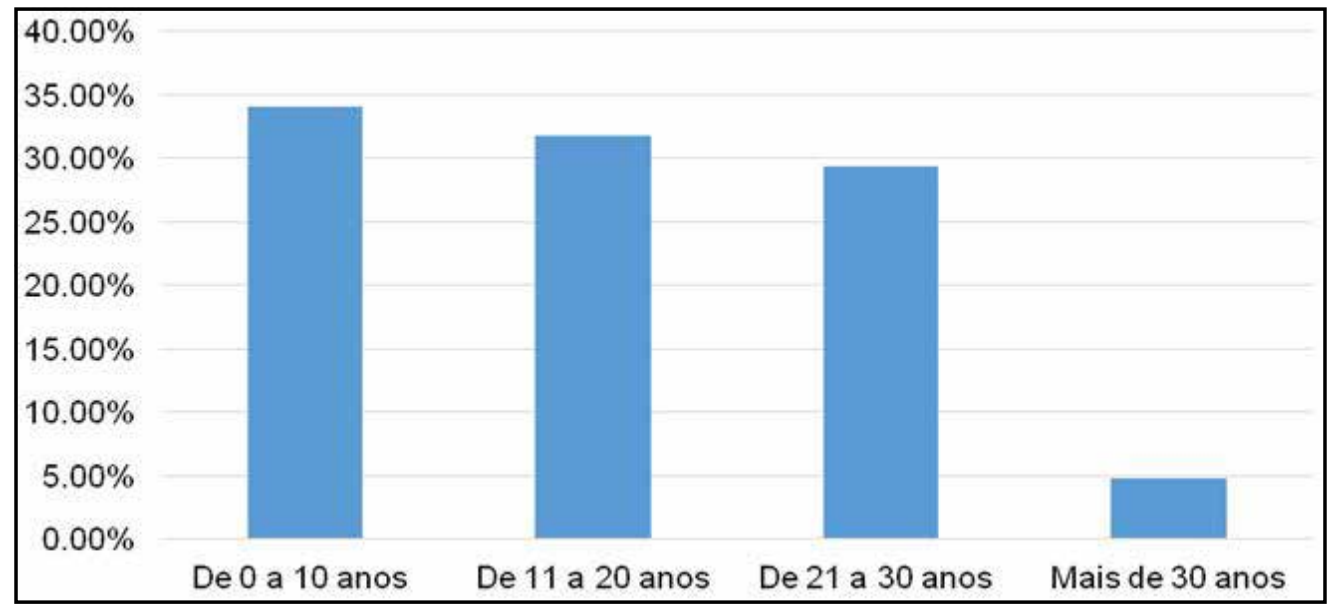

Fonte: Dados da pesquisa.

Os dados referentes ao tempo de atuação dos produtores da MROP apontam, por um lado, para um cenário de crescimento do setor, despertando grande interesse entre os proprietários rurais da região de abrangência da pesquisa. Prova disso é que $34,11 \%$ do total dos entrevistados ingressaram na avicultura nos últimos 10 anos; destes, $18,82 \%$ atuam há menos de 5 anos. A pesquisa revela também baixo índice de desistência da atividade, evidenciado pelo significativo tempo de atuação dos produtores (34,16\% atuam há mais de 20 anos na avicultura).

Confrontando os dados atinentes ao tempo de atuação dos produtores com a questão do financiamento da atividade, constatou-se que um número considerável deles ainda possui parcelas a serem pagas aos agentes financeiros referentes à construção das granjas.

Os resultados revelam que aproximadamente um terço dos aviários da MROP foi construído na última década, e que o tempo médio de contratação dos financiamentos do setor é para um prazo de dez anos. Esse cenário aponta para a necessidade de cautela em todos os elos do SAG avícola, a fim de evitar eventuais crises do setor que podem comprometer a competitividade do SAG. 


\section{CONSIDERAÇÕES FINAIS}

O sistema agroindustrial avícola existente na Mesorregião Oeste do Paraná é responsável por parcela significativa da geração de empregos de renda à população. Isso porque, além das agroindústrias responsáveis pela geração de empregos, principalmente no abate e processamento das aves, o setor dispõe de mais de 3.000 produtores rurais dedicando-se à atividade.

Como principais achados na pesquisa realizada, tem-se o fato de que a atividade é desempenhada na MROP, prioritariamente, por pequenos produtores, e regida por meio do estabelecimento de contrato de produção avícola entre produtores e agroindústrias (sistema de integração). Essa forma de relação de trabalho, conferida pelo sistema em estudo, propicia, sobretudo aos pequenos produtores, a possibilidade de obtenção de renda em um menor período, comparativamente à produção de grãos e do aproveitamento da mão de obra familiar.

Ademais, constatou-se que a avicultura é desenvolvida com significativa participação do trabalho feminino. Este trabalho afirma elevada satisfação em seu desempenho, com, inclusive, níveis de rendimentos superiores aos das granjas cujo trabaIho masculino é preeminente. Identificou-se ainda, entretanto, que a atividade é pouco atrativa aos jovens, uma vez que apenas $4 \%$ dos produtores têm idade inferior a 30 anos. Tal fato gera preocupação para a continuidade e crescimento do setor, e necessidade de um a olhar mais atento das agroindústrias a essa problemática.

Por outro lado, os dados da pesquisa apontam para um cenário positivo em relação ao grau de escolaridade do produtor, que, embora com idade avançada, possui níveis de escolaridade superior à média nacional para populações rurais. Isso denota um perfil de produtor de aves preocupado com o autodesenvolvimento e com capacidade para compreender e incorporar as mudanças tecnológicas e práticas de manejo necessárias ao bom desenvolvimento da atividade.

Outro aspecto que merece destaque diz respeito à motivação para o ingresso na atividade. Embora parcela de produtores afirme que a atividade não gera ganhos diretos e que, muitas vezes, trabalham com pequena margem de lucratividade, a possibilidade de financiamento das estruturas físicas e aparato tecnológico representa fator preponderante ao ingresso e permanência na atividade. Aliado a isso, tem-se também como motivador, de acordo com a pesquisa realizada, o fato de que o sistema de integração possibilita segurança em relação à total comercialização da produção e garantia de assistência técnica gratuita ofertada pela agroindústria; fatores que impactam positivamente na decisão de ingressar e permanecer na atividade, principalmente em se tratando de pequenos proprietários rurais, com reduzida capacidade de investimentos.

Por fim, cumpre destacar que, embora não se tivesse a pretensão de exaurir a temática, entende-se que os objetivos estabelecidos para o presente trabalho foram atingidos e contribuições foram dadas. Não se pode ignorar, no entanto, a presença de limitações no desenvolvimento do artigo e, nesse sentido, acredita-se que investigações mais aprofundadas sobre a temática podem ser desenvolvidas, incluindo, no estudo, demais aspectos inerentes a atividades, a exemplo de pesquisa sobre a forma contratual, e mesmo de extrapolação dessa análise para demais regiões produtoras de aves do Estado e do país. 


\section{REFERÊNCIAS}

AGROEMDIA. Cooperativa paranaense tem recorde de produtividade integrada de aves. Disponível em: https://agroemdia.com.br/2018/03/25/cooperativa-paranaense-tem-recorde-de-produtividade-integrada-de-aves/. Acesso em: 30 mar. 2018.

ABPA. Associação Brasileira de Proteína Animal - Relatório Anual, 2017. Disponível em: http://www. http://abpa-br.com.br/setores/avicultura/publicacoes/relatorios-anuais. Acesso em: 3 fev.

ATLAS BRASIL. Educação. Disponível em: http://www.atlasbrasil.org.br/2013/pt/perfil_uf/parana\#educacao. Acesso em: 23 maio 2019.

BARCZSZ, S. S.; LIMA FILHO, D. O. Agroindústria exportadora de frango de corte sul-mato-grossense e os aspectos de internacionalização. Revista em Agronegócios e Meio Ambiente, v. 2, n. 2, p. 9-33, maio/ago. 2009.

BARDIN, L. Análise de conteúdo. Lisboa: Edições, 2004.

CANAVER, M. D. et al. A cadeia produtiva do frango de corte no Brasil e na Argentina. Concórdia: Embrapa; CNPSA, 1997.

EMBRAPA. Empresa Brasileira de Pesquisa Agropecuária. Produção de frango de corte. 2003. Disponível em: http://www.cnpsa.embrapa.br/aves/. Acesso em: 30 mar. 2018.

FONTANELLA, B. J. B.; RICAS, J.; TURATO, E. R. Amostragem por saturação em pesquisas qualitativas: contribuições teóricas. Cadernos de Saúde Pública. 24(1), p. 17-27, 2008.

GIL, A. C. Como elaborar projetos de pesquisa. 4. ed. São Paulo: Atlas, 2009.

INCRA. Instituto Nacional de Colonização e Reforma Agrária. Sistema Nacional de cadastro rural. Disponível em: http://www.incra.gov.br/. Acesso em: 30 mar. 2018.

IPARDES. Instituto Paranaense de Desenvolvimento Econômico e Social. Análise da competitividade da cadeia agroindustrial de carne de frango no Estado do Paraná: sumário executivo. Curitiba: Ufscar, 2002. Disponível em: http://www.ipardes.gov.br/webisis.docs/cadeia_agroindustrial_aves_sumario_executivo. pdf. Acesso em: 20 fev. 2018.

IPARDES. Instituto Paranaense de Desenvolvimento Econômico e Social. Oeste Paranaense: o terceiro espaço relevante - especificidades e diversidades. 2017. Disponível em: http://www.ipardes.gov.br/index. php?pg_conteudo=1\&cod_noticia=870. Acesso em: 30 mar. 2018.

JESUS JUNIOR, C. de et al. A cadeia da carne de frango: tensões, desafios e oportunidades. Agroindústria: BNDES Setorial, 2007. Disponível em: http://www.bndes.gov.br/conhecimento/bnset/set2607.pdf. Acesso em: 10 mar. 2018.

LIMA FILHO, D. O. et al. Determinantes da compra de frango: saúde ou preço? Informações Econômicas, São Paulo, v. 35, n. 12, dez. 2005.

LIMA, M. A. A. Mudança tecnológica, organização industrial e expansão da produção de frango de corte no Brasil. 1984. Dissertação (Mestrado) - USP, Departamento de Economia, São Paulo, 1984.

MACDONALD, J. M.; KORB, P. Agricultural contracting update: contracts in 2003. Electronic report from Economic Research Service (Usda). Economic Information Bulletin, n. 9, jan. 2006. Disponível em: http:// www.ers.usda.gov. Acesso em: 15 fev. 2018.

MAPA. Ministério da Agricultura, Pecuária e Abastecimento. Aves. 2014. Disponível em: http://www.agricultura.gov.br/animal/especies/aves/notícias. Acesso em: 12 mar. 2018.

PEREIRA, C. M. M. A.; MELO, M. R.; SANTOS, M. H. O agronegócio do frango de corte: um estudo de caso sob a ótica da economia dos custos de transação. Informações Econômicas, São Paulo, v. 37, n. 1, jan. 2007.

RICHARDSON, Roberto Jarry. Pesquisa social: métodos e técnicas. São Paulo: Atlas, 1999.

RIZZI, A. T. A indústria de frangos no Brasil: constituição e transformações. In: CONGRESSO BRASILEIRO DE HISTÓRIA ECONÔMICA, CONFERÊNCIA INTERNACIONAL DE HISTÓRIA DE EMPRESAS, 2004, Belo Horizonte. Anais [...]. Belo Horizonte, 2004. Disponível em: http://www.abphe.org...99/Textos/ADAIR.pdf. Acesso em: 23 mar. 2018.

RIZZI, A. T. Mudanças tecnológicas e reestruturação da indústria agroalimentar: o caso da indústria de frangos no Brasil. Tese (Doutorado) -Unicamp, Campinas, 1993.

SALVIANO, P. A. P. Análise das relações contratuais no sistema de integração vertical de produção de aves de corte no município de Rio Verde - Goiás -, sob a ótica da nova economia institucional. 2011, 92 f. Dissertação (Mestrado em Desenvolvimento Regional) - Faculdades Alves Faria, Goiânia, 2011.

SEAB. Secretaria da Agricultura e do Abastecimento do Paraná. Conjuntura agropecuária. Disponível em: http://www.agricultura.pr.gov.br/. Acesso em: 5 mar. 2018. 
UBABEF. União Brasileira de Avicultura. Relatório anual, 2011. Disponível em: http://www.ubabef.com. br/publicacoes. Acesso em: 3 fev. 2018.

UBABEF. União Brasileira de Avicultura. Relatório anual, 2013. Disponível em: http://www.ubabef.com. br/publicacoes. Acesso em: 3 fev. 2018.

UBABEF. União Brasileira de Avicultura. Relatório anual, 2014. Disponível em: http://www.ubabef.com. br/publicacoes. Acesso em: 3 fev. 2018.

WILKINSON, J. Estudo da competitividade da indústria brasileira: competitividade na indústria de abate e preparação de carnes. Campinas: IE; Unicamp; IEI; UFRJ; FDC-Funcex, 1993. Disponível em: http://www. dominiopublico.gov.br/download/texto/ci000044.pdf. Acesso em: 18 jan. 2018.

ZILLI, J. B. Os fatores determinantes para a eficiência econômica dos produtores de frango de corte: uma análise estocácia. 2003. 130f. Dissertação (Mestrado em Economia Aplicada) - Universidade de São Paulo, Escola Superior de Agricultura Luiz de Queiroz, Piracicaba, 2003. 